\title{
Autograft diameter in ACL reconstruction: size does matter
}

\author{
Fahad N. A. Alkhalaf, Sager Hanna, Mohammed Saleh Hattab Alkhaldi, Fares Alenezi, and Aliaa Khaja* \\ Al Razi Orthopedic Hospital, Kuwait
}

Received 27 November 2020, Accepted 28 February 2021, Published online 22 March 2021

\begin{abstract}
Background: Anterior cruciate ligament injuries are commonly seen in orthopedic surgery practice. Although anterior cruciate ligament reconstruction (ACLR) has come a long way, the causes of failure have yet to be fully understood. Objective: The aim of this study was to investigate whether or not the intraoperative 4-strand hamstring autograft diameter does in fact influence the failure rates of ACLR. Methods: Retrospective intraoperative data were collected from ACLR patients from the only tertiary center available in Kuwait. Patients who underwent ACLR from 2012 to 2018 for isolated ACL injuries were included in this study, allowing for a 24 month follow-up period The cohorts were categorized into 3 groups: patients with graft size $\leq 8 \mathrm{~mm}, 2$, patients with graft sizes $\geq 8 \mathrm{~mm}$ with 4-strands and patients with graft sizes $\geq 8 \mathrm{~mm}$ with 4-strands or more. ANOVA analysis was applied to address group differences between mean graft size and strand numbers and subsequently the failure rates for each group. In addition, the Mann-Whitney $U$ test was used to investigate the relationship between revision and initial ACL graft size. Results: Out of the 711 out of 782 patients were included in this study. Only $42.6 \%$ of the patients did not need more than 4-strands to achieve an $8 \mathrm{~mm}$ sized autograft. The patients who had autografts $\leq 8 \mathrm{~mm}$ in this study accounted for $17.1 \%$ of the population. About $7.2 \%$ of these patients required revision surgery. Patients with a 4-strand autograft size that was less than $8 \mathrm{~mm}$ were 7.2 times more at risk for ACLR failure (RR = 7.2, 95\% CI: 6.02; 8.35, $p=0.007$ ). Conclusions: There is a significant correlation between 4-strand autograft diameter size and the need for ACLR revision surgery.
\end{abstract}

Level of Evidence: IV case series.

Key words: ACL, Hamstring graft, Arthroscopy, Joint surgery.Level of Evidence: IV case series.

\section{Introduction}

Most of the patients undergo reconstruction of the ACL based on destabilizing symptoms or the urge to participate in pivoting or cutting sports $[1,2]$. While the gold standard for reconstruction has always been the bone-patellar tendon-bone (BPTB). The literature has reported figures as high as $30 \%$ of BPTB patients suffering from chronic anterior knee pain $[3,4]$. This is why the quadrupled hamstring tendon option has become the mainstay practice in Kuwait for anterior ACLR $[3,4]$. The reason being for this trend in Kuwaiti orthopedic surgical practice is that the cultural behaviors and daily living practices would be exacerbated by the BPTB related anterior knee pain should it happen [5-7].

However, one of the downfalls of using hamstring autografts as opposed to BPTB grafts is the success of the surgery relies on larger diameter grafts [8]. Major studies have suggested that the autograft hamstring diameter should ideally

\footnotetext{
*Corresponding author: aliaa.khaja@gmail.com
}

range between 7 and $10 \mathrm{~mm}$ to avoid failure [9, 10]. And the current recommendations advocate for the use of hamstring autografts with a size of $8 \mathrm{~mm}$ or above [11-13].

Although accurate preoperative autograft size prediction is difficult, clinical studies have shown that the diameter of the hamstring autograft correlates with patient height, gender, thigh circumference and BMI [13, 14].

The size of the hamstring tendon can be accurately determined by non-invasive methods such as magnetic resonance imaging (MRI) or ultrasound imaging [9-11]. The imaging modality of choice depends on what is available in medical centers. However, ultrasound has been proven to be more accurate in predicting the autograft size in the hands of an experienced operator than an MRI scan [9-11].

In terms of ACLR and risks of deep infections, BPTB grafts have significantly lower risks of deep infections followed by hamstring tendon grafts, leaving allografts with the highest infection risk [12].

The authors of this study initially hypothesized that the Kuwaiti population generally produces smaller four-strand hamstring autografts thus accounting for the need for higher 


\section{HISTOGRAM OF AGE}

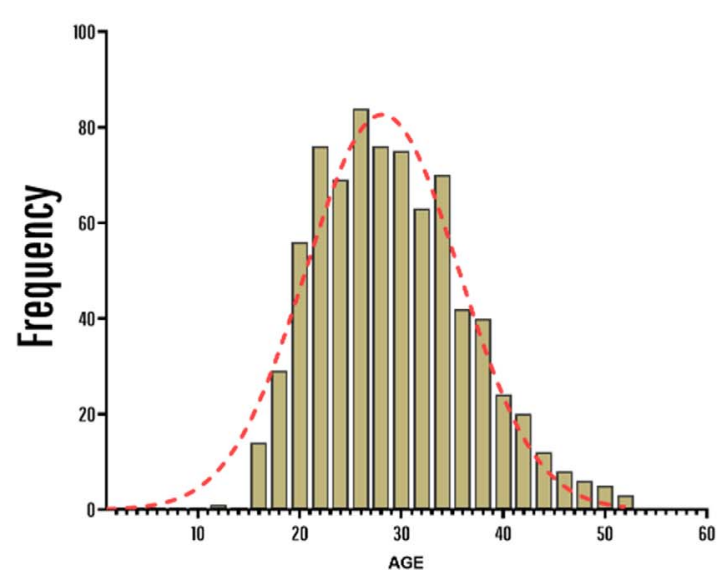

PERCENTAGE DISTRIBUTION OF AGE GROUPS

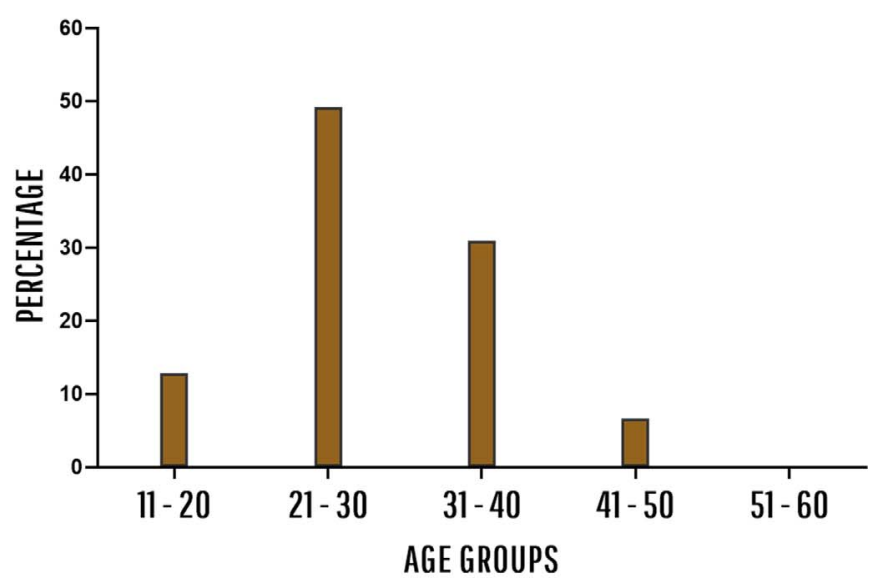

Figure 1. Histogram of Age and distribution plot of different age groups. Around 50\% of all ACL patients were at the age between 21 and 30 , while $30 \%$ of them were between 31 and 40 years old.

revision rates [6]. The objective of this study was to investigate the population's general anatomical size of their intra-operative hamstring autograft and ascertain whether or not the size of the autograft influenced our ACL revision rates. Our null hypothesis was that there would be no correlation between ACLR failure rate and diameter size. The current number of the Kuwaiti population was estimated to be around 5 million people, with the Kuwaitis accounting for $20 \%$ of that number [5, 6, 15]. This study was conducted in a tertiary center with the only ACLR facility in the country. Thus, all the ACLR in the country were performed by this unit.

\section{Methods}

The data was collected retrospectively from records held by the only ACLR unit in the country. The authors included the surgical records of patients who had isolated ACL injuries from the 1st January 2012 until the 31st of May 2018 with a minimum of 2-year follow-up required. Only patients who underwent the trans-portal anatomical reconstruction with hybrid fixation and suspensory fixation on the femur with an interference screw on the tibia [14] or the all-inside method using Arthrex ${ }^{\circledR}$ equipment were included $[4,16]$.

Patients who had their ACLR surgeries outside of Kuwait were excluded as well as patients with incomplete operative notes, missing files, and patients with lost follow-up records. Professional or contact athletes were also excluded. Three of the authors collected the relevant information from the patient's operative and follow-up notes. The data collected from 3 separate data forms were then cross-referenced to identify any errors or conflicting information to assure for accuracy of the results. The patients were sorted into subgroups according to autograft size, number of strands, and need for augmentation. The patients in this study were categorized into three groups; less than $8 \mathrm{~mm}, 8-9 \mathrm{~mm}$, and more than $9 \mathrm{~mm}$.

To investigate the relationship between primary ACLR autograft size and the number of strands used in the surgery, three statistical methods were used. First, ANOVA was applied
Table 1. Descriptive analysis of age and final graft size.

\begin{tabular}{lccc}
\hline \multicolumn{4}{c}{ Descriptive analysis } \\
\hline Age & $\begin{array}{c}\text { Final graft } \\
\text { size (mm) }\end{array}$ & $\begin{array}{c}\text { Number } \\
\text { of strands }\end{array}$ \\
\hline Mean & 28.72 & 8.28 & 4.65 \\
Median & 28.00 & 8.00 & 4 \\
Mode & 22.00 & 8.00 & 4 \\
Minimum & 12.00 & 6.00 & 3 \\
Maximum & 52.00 & 11.00 & 10 \\
\hline
\end{tabular}

to find out the between-group differences of mean graft size among different numbers of strands. Next, the graft sizes were categorized into different dummy variables as the outcome and categorized the number of strands as predictors. In such a way that the relative risk (RR) of graft failure of different graft sizes for a different number of strands could be calculated. To assess the relationship between revision rates and the initial autograft, a paired t-test was performed. Chi-square tests and MannWhitney- $U$ tests were used to assess for age as a risk factor for revision surgery.

\section{Results}

Out of the 782 isolated ACLR cases, $71(9.1 \%)$ of them had no record of their graft size. Out of the 711 patients included in this study, 11 patients had an ACLR revision (failure rate $2.1 \%$ ), 9 of them were patients from the $\leq 8 \mathrm{~mm}$ graft size group.

Figure 1 and Table 1, summarize the study population demographics. The mean graft size of the sample was $8.285 \mathrm{~mm}$ (Table 2) and graft sizes $\leq 8 \mathrm{~mm}$ were used in $17.1 \%$ of all surgeries. The relationship between intraoperative graft size and the number of strands can be appreciated from Table 3, the median number of strands was 4 (53.0\%).

Table 4 shows that the quadrupled (4-strand) hamstring tendon autografts had the lowest size $(8.056 \mathrm{~mm} \pm 0.63)$. 
Table 2. Percentages and Counts for different types of augmentation in different groups of graft size/strand.

\begin{tabular}{|c|c|c|c|c|c|c|c|c|c|c|}
\hline \multirow[t]{2}{*}{ Graft size/strand } & \multicolumn{2}{|c|}{$\begin{array}{c}\text { Material } \\
\text { unknown }\end{array}$} & \multicolumn{2}{|c|}{ Lars } & \multicolumn{2}{|c|}{ Nylon } & \multicolumn{2}{|c|}{ No augmentation } & \multicolumn{2}{|c|}{ Total augmented } \\
\hline & $\%$ & Count & $\%$ & Count & $\%$ & Count & $\%$ & Count & $\%$ & Count \\
\hline$<8 \mathrm{~mm}$ & 0.00 & 0 & 6.00 & 6 & 2.00 & 2 & 92.00 & 92 & 8.00 & 8 \\
\hline$\geq 8$ \& 4-strand & 0.40 & 1 & 3.21 & 8 & 1.20 & 3 & 95.18 & 237 & 4.82 & 12 \\
\hline$\geq 8 \& \neq 4$-strand & 0.00 & 0 & 2.14 & 5 & 0.43 & 1 & 97.44 & 228 & 2.56 & 6 \\
\hline Total & 0.17 & 1 & 3.26 & 19 & 1.03 & 6 & 95.54 & 557 & 4.46 & 26 \\
\hline
\end{tabular}

The 4-strand hamstring tendon autograft size was significantly lower than the 5-strand $(\mathrm{MD}=-0.26 \pm 0.05, p<0.001)$, the 6-strand $(\mathrm{MD}=-0.56 \pm 0.14, p=0.001)$, the 7-strand $(\mathrm{MD}=-1.34 \pm 0.20, p<0.001)$, and the 8 -strand $(\mathrm{MD}=$ $-1.07 \pm 0.22, p<0.001$ ) hamstring autografts.

According to Figure 2, a 4-strand hamstring autograft size is 1.6 times more likely to be $\leq 8 \mathrm{~mm}(\mathrm{RR}=1.613,95 \% \mathrm{CI}: 1.46$, $1.75)$, and this relative risk decreases as for the graft sizes $\leq 8.5 \mathrm{~mm}$ and $\leq 9 \mathrm{~mm}$. On the other hand, the relative risk of 5-strand hamstring autograft size to be $\leq 8 \mathrm{~mm}$ was significantly lower $(\mathrm{RR}=0.75,95 \% \mathrm{CI}: 0.61 ; 0.90, p=0.025)$. This relative risk increases for graft sizes $\leq 8.5 \mathrm{~mm}(\mathrm{RR}=0.92$, 95\% CI: $0.83 ; 1.01, p=0.071)$ and $\leq 9 \mathrm{~mm}(\mathrm{RR}=1.03$, $95 \%$ CI: $0.99 ; 1.06, p=0.083)$. The initial graft size of patients who did not need any revision had a statistically and significantly greater impact compared with those who underwent the revision surgery $(\mathrm{RR}=7.2,95 \% \mathrm{CI}: 6.02 ; 8.35, p=0.007)$. Patients who had an initial autograft size of less than $8 \mathrm{~mm}$, were 7.2 times more likely to need revision surgery.

About $4.46 \%$ of all surgeries used some type of augmentation. The most common material used for augmentation was LARS $^{\circledR}$ with $3.26 \%$, while only $1.03 \%$ of all autografts were augmented with Nylon (Figure 3 ). There was an odds ratio of 0.27 (95\% CI: 0.09 ; 0.85) with augmentation use is 4-strand autografts that were smaller than $8 \mathrm{~mm}$. However, there was no statistically significant difference observed among different graft size/strand categories $\left(\chi^{2}(8)=8.079, p=0.426\right)$.

\section{Discussion}

ACLR failure is multifactorial, the current literature agrees that the diameter size of the autograft is a major contributor to ACLR failures. There have been general ranges recommended regarding the best size for the graft $[13,16,17]$. This study's results show a clear correlation between the hamstring autograft size smaller than 8 and the risk of revision in our study cohort. From this study, we can significantly ascertain that 4-strand hamstring autografts of at least $8 \mathrm{~mm}$ decreases the risk of revision rates.

The Authors understand that this study has several limitations due to scarce or unavailable data regarding the study population [18]. They did not measure the posterior tibial slope, activity level, insertion site as well as intercondylar notch of each patient. These are known contributors to ACL surgery failure rates [19]. The literature has reported that females suffer from ACL ruptures in females 2-4 times more than their male counterparts, however, our sample size only had 6 females in total so they were excluded from this study $[4,19]$. The authors
Table 3. Number of strands, their frequency and percentage distribution, and the mean initial graft size for different strand configurations.

\begin{tabular}{lcccc}
\hline Strand & Frequency & Percentage & \multicolumn{2}{c}{ Initial graft size } \\
\cline { 3 - 5 } & & & Mean & SD \\
\hline 3 & 2 & 0.3 & 9.500 & 0.710 \\
4 & 379 & 53.0 & 8.056 & 0.630 \\
5 & 266 & 37.4 & 8.317 & 0.589 \\
6 & 29 & 4.1 & 8.614 & 0.723 \\
7 & 11 & 1.6 & 9.400 & 0.690 \\
8 & 12 & 1.8 & 9.125 & 0.744 \\
9 & 11 & 1.5 & 9.250 & 1.060 \\
10 & 1 & 0.2 & & \\
\hline
\end{tabular}

Table 4. Post hoc test (Tukey HSD) - multiple comparisons of number of strands.

\begin{tabular}{|c|c|c|c|c|c|c|}
\hline \multicolumn{7}{|c|}{ Post hoc test (Tukey HSD) } \\
\hline \multicolumn{2}{|c|}{$\begin{array}{l}\text { Number } \\
\text { of strands }\end{array}$} & \multirow{2}{*}{$\begin{array}{c}\text { Mean } \\
\text { difference } \\
(I-J)\end{array}$} & \multirow[t]{2}{*}{$\begin{array}{l}\text { Std. } \\
\text { error }\end{array}$} & \multirow[t]{2}{*}{$p$} & \multicolumn{2}{|c|}{$95 \% \mathrm{CI}$} \\
\hline$I$ & $J$ & & & & Lower & Upper \\
\hline \multirow[t]{6}{*}{3} & 4 & 1.4435 & 0.4416 & 0.020 & 0.137 & 2.750 \\
\hline & 5 & 1.1826 & 0.4422 & 0.107 & -0.126 & 2.491 \\
\hline & 6 & 0.8864 & 0.4597 & 0.463 & -0.474 & 2.247 \\
\hline & 7 & 0.1000 & 0.4822 & 1.000 & -1.327 & 1.527 \\
\hline & 8 & 0.3750 & 0.4921 & 0.988 & -1.081 & 1.831 \\
\hline & 9 & 0.2500 & 0.6225 & 1.000 & -1.592 & 2.092 \\
\hline \multirow[t]{5}{*}{4} & 5 & -0.2609 & 0.0549 & 0.000 & -0.423 & -0.098 \\
\hline & 6 & -0.5572 & 0.1373 & 0.001 & -0.964 & -0.151 \\
\hline & 7 & -1.3435 & 0.2000 & 0.000 & -1.935 & -0.752 \\
\hline & 8 & -1.0685 & 0.2229 & 0.000 & -1.728 & -0.409 \\
\hline & 9 & -1.1935 & 0.4416 & 0.099 & -2.500 & 0.113 \\
\hline \multirow[t]{4}{*}{5} & 6 & -0.2963 & 0.1392 & 0.337 & -0.708 & 0.116 \\
\hline & 7 & -1.0826 & 0.2013 & 0.000 & -1.678 & -0.487 \\
\hline & 8 & -0.8076 & 0.2241 & 0.006 & -1.471 & -0.145 \\
\hline & 9 & -0.9326 & 0.4422 & 0.349 & -2.241 & 0.376 \\
\hline \multirow[t]{3}{*}{6} & 7 & -0.7864 & 0.2374 & 0.017 & -1.489 & -0.084 \\
\hline & 8 & -0.5114 & 0.2570 & 0.422 & -1.272 & 0.249 \\
\hline & 9 & -0.6364 & 0.4597 & 0.810 & -1.997 & 0.724 \\
\hline \multirow[t]{2}{*}{7} & 8 & 0.2750 & 0.2953 & 0.967 & -0.599 & 1.149 \\
\hline & 9 & 0.1500 & 0.4822 & 1.000 & -1.277 & 1.577 \\
\hline 8 & 9 & -0.1250 & 0.4921 & 1.000 & -1.581 & 1.331 \\
\hline
\end{tabular}

Bold value denotes more significant findings.

theorize that this could be due to cultural reasons that generally discourage females from pursuing athletic careers [4-6].

In Kuwait, only $42.6 \%$ of our sample size had delivered a 4-strand $8 \mathrm{~mm}$ diameter hamstring autograft. About $40.2 \%$ of 


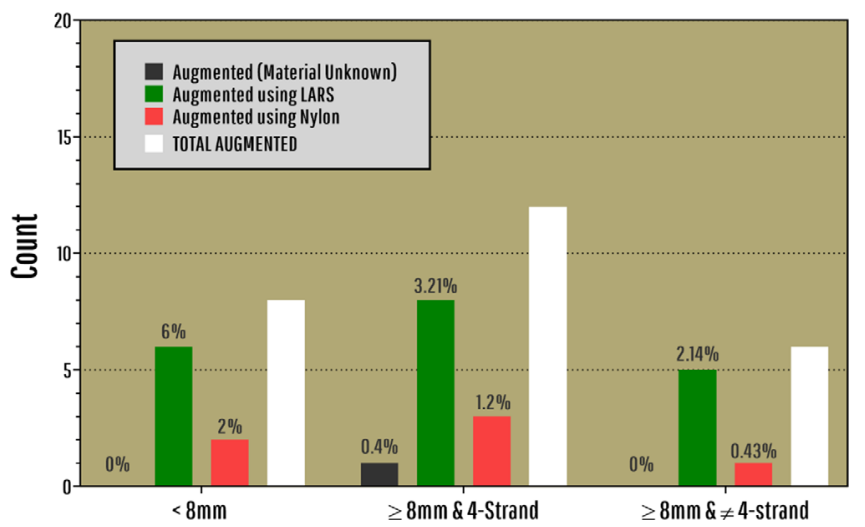

Figure 2. Bar Plot illustrating the number of augmentations and the materials used. In addition, the percentage of each augmentation is written on top of the bars.

our patients needed more than 4 strands to achieve reach $8 \mathrm{~mm} \pm$ augmentation. Meaning that achieving the desired $8 \mathrm{~mm}$ can prove to be challenging [20-22]. However, this finding is in keeping with findings from other populations, mainly in North America [13, 17, 21]. When comparing our data with the largest cohort available on hamstring graft size in ACLR, the percentage of patients that had autografts with 4-strands sized $\geq 8 \mathrm{~mm}$ without augmentation was also around $37.9 \%$ [13, 17, 22-24]. Whereas in South India, a similar study to ours showed that $\geq 8 \mathrm{~mm}$ grafts can be produced using only 3 -strands in $46 \%$ of their patients [25].
Table 5. Comparison table of results found by large-scale studies.

\begin{tabular}{|c|c|c|}
\hline & $\begin{array}{l}\text { Number of } \\
\text { patients }\end{array}$ & Main findings \\
\hline $\begin{array}{l}\text { MOON Cohort } \\
\text { Study }\end{array}$ & 263 & $\begin{array}{l}\text { Revision was required in } 0 \text { of } 61 \\
\text { patients }(0.0 \%) \text { with grafts } \\
\text { greater than } 8 \mathrm{~mm} \text { in diameter } \\
\text { and } 14 \text { of } 202 \text { patients }(6.5 \%) \\
\text { with } 8 \mathrm{~mm} \text { or smaller grafts } \\
(p=0.037)\end{array}$ \\
\hline $\begin{array}{l}\text { Snaebjörnsson } \\
\text { et al. [15] }\end{array}$ & $\begin{array}{c}\text { Cases: } 560 \\
\text { Controls: } \\
1680\end{array}$ & $\begin{array}{l}\text { The likelihood of revision } \\
\text { surgery for every } 0.5-\mathrm{mm} \\
\text { increase in the HT autograft } \\
\text { diameter between } 7.0 \text { and } \\
10.0 \mathrm{~mm} \text { was } 0.86(95 \% \mathrm{CI} \text { : } \\
0.75-0.99 ; p=0.03)\end{array}$ \\
\hline $\begin{array}{l}\text { Alkhalaf et al. (this } \\
\text { study) }\end{array}$ & 711 & $\begin{array}{l}\text { Patients with a } 4 \text {-strand autograft } \\
\text { size that was less than } 8 \mathrm{~mm} \\
\text { were } 7.2 \text { times more at risk for } \\
\text { ACLR failure (RR } 7.2,95 \% \\
\text { CI: } 6.02 ; 8.35, p=0.007 \text { ) }\end{array}$ \\
\hline
\end{tabular}

While considerable success in the restoration of knee stability has been demonstrated in ACLR, recent studies indicate that between 1.8 and $22 \%$ of primary grafts will still fail globally and require revision if they are less than $8 \mathrm{~mm}$ in diameter [25-27]. Our population results fall into the lower end (2.1\%) of these internationally reported rates of revision [28-30]. From the $17.1 \%$ of patients with autografts $\leq 8 \mathrm{~mm}$ in our study, about $7.2 \%$ needed a revision. In the MOON study, of the

\section{Relative risk of final graft size for different number of strands}

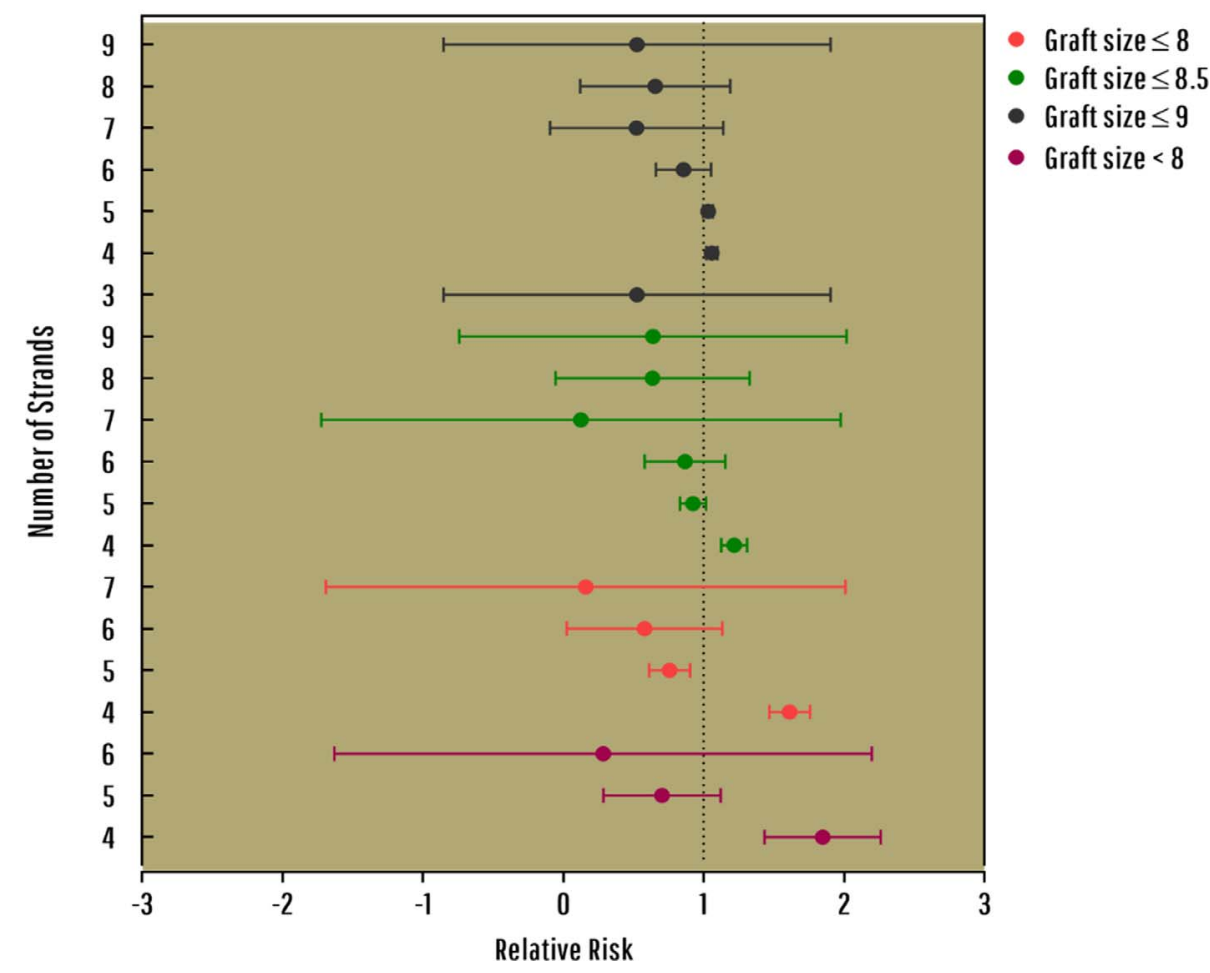

Figure 3. Relative risk (RR) of final graft sizes for different number of strands. 
$62.1 \%$ of the patients with grafts $\leq 8 \mathrm{~mm}, 15.3 \%$ needed revision $[13,14,17]$. On the other hand, the South Indian cohort had $12 \%$ of their autografts less than $\leq 7 \mathrm{~mm}$ and only $12 \%$ of them needed a revision $[31,32]$. Table 5 , is a summary of the main findings of this study compared with the large-scale studies discussed.

Our study did not record a significant statistical difference between age and failure. However, the current evidence appearing in studies shows that revision is most common in the active and young population [33-37].

\section{Conclusion}

Although the causes for ACLR failure rates can be attributed to multiple confounding factors, this study concluded that there is a high association between the autograft diameter size and the need for revision surgery. The 4-strand hamstring autograft diameter of less than $8 \mathrm{~mm}$ does correlate with an increased risk of ACLR failure rates. This study shows that patients who had an ACLR with a 4-strand autograft size of less than $8 \mathrm{~mm}$ were 7.2 times more likely to require a revision.

\section{Source of funding}

The authors received no specific funding for this work.

\section{Ethical approval}

The Kuwaiti Ministry of Health Ethical Committee is the main authority of patient record keeping, and they had approved this study. Committee Reference Number: 2019/1069.

\section{Conflicts of interest}

The authors declare they have no conflicts of interest in relation to this article.

\section{References}

1. Hewett TE, Schultz SJ, Griffin LY, Editors (2007) Understanding and preventing noncontact ACL injuries. Champaign, IL, Human Kinetics.

2. Ahlden M, Samuelsson K, Sernert N, Forssblad M, Karlsson J, Kartus J (2012) The Swedish national anterior cruciate ligament register: A report on baseline variables and outcomes of surgery for almost 18,000 patients. Am J Sports Med 40, 2230-2235.

3. Hamner DL, Brown CH Jr, Steiner ME, Hecker AT, Hayes WC (1999) Hamstring tendon grafts for reconstruction of the anterior cruciate ligament: Biomechanical evaluation of the use of multiple strands and tensioning techniques. J Bone Joint Surg Am 81, 549-557.

4. Hamido F, Al Harran H, Al Misfer AR, El Khadrawe T, Morsy MG, Talaat A, Elias A, Nagi A (2015) Augmented short undersized hamstring tendon graft with LARS $^{\circledR}$ artificial ligament versus four-strand hamstring tendon in anterior cruciate ligament reconstruction: Preliminary results. Orthop Traumatol Surg Res 101(5), 535-538.
5. Hanna SS, AlKhalaf F, AlSamhan A, AlHamdan HA, AlAdwani BM, Khaja A (2020) Translation, adaptation and validation of the middle east lower limb score (MELLS) into Arabic. Int J Innov Res Med Sci 5(11), 488-492.

6. Maqdes A, Hanna SS, Bouhamra AK, Khaja AF (2020) Crosscultural adaptation and translation of the Constant Murley Score into Arabic. SICOT-J 6, 44.

7. Wilson TW, Zafuta MP, Zobitz M (1999) A biomechanical analysis of matched bone-patellar tendon-bone and doublelooped semitendinosus and gracilis tendon grafts. Am J Sports Med 27, 202-207.

8. Ma CB, Keifa E, Dunn W, Fu FH, Harner CD (2010) Can preoperative measures predict quadruple hamstring graft diameter? Knee 17, 81-83.

9. Schwartzberg R, Burkhart B, Lariviere C (2008) Prediction of hamstring autograft diameter and length for anterior cruciate reconstruction. Am J Orthop 37, 157-159.

10. Treme G, Diduch DR, Billante MJ, Miller MD, Hart JM (2008) Hamstring graft size prediction: A prospective clinical evaluation. Am J Sports Med 36, 2204-2209.

11. Tuman JM, Diduch DR, Rubino LJ, Baumfeld JA, Nguyen HS, Hart JM (2007) Predictors for hamstring graft diameter in anterior cruciate ligament reconstruction. Am J Sports Med 35, 1945-1949.

12. Bansal A, Lamplot JD, VandenBerg J, Brophy RH (2018 May) Meta-analysis of the risk of infections after anterior cruciate ligament reconstruction by graft type. Am J Sports Med 46(6), 1500-1508.

13. Magnussen RA, Lawrence JT, West RL, Toth AP, Taylor DC, Garrett WE (2012) Graft size and patient age are predictors of early revision after anterior cruciate ligament reconstruction with hamstring autograft. Arthroscopy 28, 526-531.

14. Mariscalco MW, Flanigan DC, Mitchell J, Pedroza AD, Jones MH, Andrish JT, Magnussen RA (2013) The influence of hamstring autograft size on patient- reported outcomes and risk of revision after anterior cruciate ligament reconstruction: A multicenter orthopaedic outcomes network (MOON) cohort study. Arthrosc J Arthrosc Relat Surg 29(12), 1948-1953.

15. Snaebjörnsson T, Hamrin Senorski E, Ayeni OR, et al. (2017) Graft diameter as a predictor for revision anterior cruciate ligament reconstruction and KOOS and EQ-5D values: A cohort study from the Swedish National Knee Ligament Register based on 2240 patients. Am J Sports Med 45(9), 2092-2097.

16. Alhendi B, Al-Saifi S, Khaja A (2020) Medical tourism overseas: A challenge to Kuwait's Healthcare System. Int J Travel Med Glob Health 8(1), 22-30.

17. Kaeding CC, Aros B, Pedroza A, et al. (2011) Allograft versus autograft anterior cruciate ligament reconstruction: Predictors of failure from a MOON prospective longitudinal cohort. Sports Health 3, 73-81.

18. Wright RW, Magnussen RA, Dunn WR, Spindler KP (2011) Ipsilateral graft and contralateral ACL rupture at five years or more following ACL reconstruction: A systematic review. J Bone Joint Surg Am 93, 1159-1165.

19. Figueroa F, Figueroa D, Espregueira-Mendes J (2018) Hamstring autograft size importance in anterior cruciate ligament repair surgery. EFORT Open Rev 3(3), 93-97.

20. Grassi A, Kim C, Marcheggiani Muccioli GM, Zaffagnini S, Amendola A (2017) What is the mid-term failure rate of revision ACL reconstruction? A systematic review Clin Orthop Relat Res ${ }^{\circledR}$ 475(10), 2484-2499. 
21. Goyal T, Paul S, Das L, Choudhury AK (2020) Correlation between anthropometric measurements and activity level on length and diameter of semitendinosus tendon autograft in knee ligament surgery: A prospective observational study. SICOT-J 6, 23.

22. Imam MA, Abdelkafy A, Dinah F, Adhikari A (2015) Does bone debris in anterior cruciate ligament reconstruction really matter? A cohort study of a protocol for bone debris debridement. SICOT J 1, 4.

23. Leo BM, Krill M, Barksdale L, Alvarez-Pinzon AM (2016) Failure rate and clinical outcomes of anterior cruciate ligament reconstruction using autograft hamstring versus a hybrid graft. Arthrosc J Arthrosc Relat Surg 32(11), 2357-2363.

24. Sanders TL, Pareek A, Hewett TE, Levy BA, Dahm DL, Stuart MJ, Krych AJ (2016) Long-term rate of graft failure after ACL reconstruction: A geographic population cohort analysis. Knee Surg Sports Traumatol Arthrosc 25(1), 222-228.

25. Shelbourne KD, Gray T, Haro M (2009) Incidence of subsequent injury to either knee within 5 years after anterior cruciate ligament reconstruction with patellar tendon autograft. Am J Sports Med 37, 246-251.

26. Barrett AM, Craft JA, Replogle WH, Hydrick JM, Barrett GR (2011) Anterior cruciate ligament graft failure: A comparison of graft type based on age and Tegner activity level. Am J Sports Med 39, 2194-2198.

27. Challa S, Satyaprasad J (2013) Hamstring graft size and anthropometry in south Indian population. J Clin Orthop Trauma 4(3), 135-138.

28. Borchers JR, Pedroza A, Kaeding C (2009) Activity level and graft type as risk factors for anterior cruciate ligament graft failure: A case-control study. Am J Sports Med 37, 2362-2367.

29. Reinke EK, Spindler KP, Lorring D, et al. (2011) Hop tests correlate with IKDC and KOOS at minimum of 2 years after primary ACL reconstruction. Knee Surg Sports Traumatol Arthrosc 19, 1806-1816.
30. Lubowitz JH, Amhad CH, Anderson K (2011) All-inside anterior cruciate ligament graft-link technique: Second-generation, no-incision anterior cruciate ligament reconstruction. Arthrosc J Arthrosc Relat Surg 27(5), 717-727.

31. Owusu-Akyaw KA, Kim SY, Spritzer CE, Collins AT, Englander ZA, Utturkar GM, Garrett WE, DeFrate LE (2018) Determination of the position of the knee at the time of an anterior cruciate ligament rupture for male versus female patients by an analysis of bone bruises. Am J Sports Med 46(7), 1559-1565.

32. Napier RJ, Garcia E, Devitt BM, Feller JA, Webster KE (2019) Increased radiographic posterior tibial slope is associated with subsequent injury following revision anterior cruciate ligament reconstruction. Orthop J Sports Med 7(11).

33. Andernord D, Desai N, Bjornsson H, Gillen S, Karlsson J, Samuelsson K (2015) Predictors of contralateral anterior cruciate ligament reconstruction: A cohort study of 9061 patients with 5-year follow-up. Am J Sports Med 43(2), 295-302.

34. Andernord D, Desai N, Bjornsson H, Ylander M, Karlsson J, Samuelsson K (2015) Patient predictors of early revision surgery after anterior cruciate ligament reconstruction: A cohort study of 16,930 patients with 2-year follow-up. Am J Sports Med 43(1), 121-127.

35. Kopf S, Pombo M, Szczodry M, Irrgang J, Fu F (2011) Size variability of the human anterior cruciate ligament insertion sites. Am J Sports Med 39(1), 108-113.

36. Guenther D, Irarrázaval S, Albers M, Vernacchia C, Irrgang JJ, Musahl V, Fu FH (2017) Area of the tibial insertion site of the anterior cruciate ligament as a predictor for graft size. Knee Surg Sports Traumatol Arthrosc 25, 1576-1582.

37. Dhanakodi N, Thilak J, Varghese J, Menon KV, Varma HK, Tripathy SK (2019) Ceramic bone graft substitutes do not reduce donor-site morbidity in ACL reconstruction surgeries: A pilot study. SICOT-J 5, 14. 